\title{
Predicting model of thickness distribution and rolling force in angular rolling process based on influence function method
}

\author{
Pujun Hao, Anrui He*, and Wenquan Sun \\ National Engineering Research Center of Advanced Rolling, University of Science and Technology Beijing, Beijing 100083, \\ PR China
}

Received: 9 January 2018 / Accepted: 25 April 2018

\begin{abstract}
As a special rolling method, angular rolling can meet various gauge demands of customized production. Due to the asymmetry of angular rolling, the rolling forces on the two sides of the roll system are different and the thickness distribution of the plate will be complex. To accurately obtain the thickness distribution and predict the rolling force during the angular rolling process, a mathematical model based on the influence function method is developed. An experiment is also adopted to validate the results of the rolling force. The results show that the change in the total rolling force comprises three stages: increasing, stable, and decreasing. During most of the rolling time, the rolling forces on the two sides of the mill are different. Then the predicted results of the rolling force are validated by experiment. After the first pass of angular rolling, a serious wedge appears at the head and tail ends of the plate. But when the angular rolling is finished, the wedge has almost disappeared. Considering the short calculation time, this model can be applied in the actual production process for making effective shape control strategies and flexible rolling schedules to meet various gauge demands of customized production.
\end{abstract}

Keywords: Aluminium alloy / influence function method / angular rolling / thickness distribution / rolling force

\section{Introduction}

Aluminium alloy thick plate is widely used in the automobile, aerospace, and marine industries due to its excellent corrosion resistance and specific strength. To meet the demand for various gages of aluminium alloy thick plate, angular rolling [1] is adopted in the upstream of hot rough rolling. The process of angular rolling is shown in Figure 1 . The sizes of the plates can be controlled flexibly by controlling the rotation angle of plate to meet the demand for customized production.

Because the plate rotates in the horizontal plane before angular rolling, the distribution of metal in the deformation zone becomes asymmetric about the rolling central line. Then the rolling forces on the two sides of the rolling mill are not equal, so the loaded roll gap becomes asymmetric. According to the location of metal in the deformation zone and the loaded roll gap, the shape of the cross-section can be obtained to investigate the deformation of the plate and shape control.

At present, due to advanced computer performances, the finite element method is the most popular method of

\footnotetext{
* e-mail: harui_ustb@163.com
}

researching the elastic deformation of roll systems. Wu et al. [2] established a three-dimensional elastic-plastic finite element model of rolls and thermal deformation of the work roll using ABAQUS. Sun et al. [3] presented a finite element model for the prediction of thermal behaviour of the strip occurring in the finishing mill during hot strip rolling and the accuracy was validated by measurement. Ding et al. [4] researched the rolling process of AM60 sheets with a $50 \%$ reduction using DEFORM and found the law of change of metal flow velocity and distribution of strain. Peng et al. [5] performed a three-dimensional thermalmechanical coupled simulation of 5052 aluminium alloy during hot rolling with multi-parameters. Song et al. [6] researched the head and tail defect formation of 3003 aluminium alloy hot rolling and developed an optimization method with MRAC. Zhang et al. [7] established an integrated simulation model of rolls and strip based on the finite element software ABAQUS to study the generation of the transverse thickness deviation of a soft, wide, thin steel strip in the tandem cold rolling process. A number of scholars have also calculated the deformation of roll systems using the finite element method [8-12] in both the steel and the nonferrous metal area.

However, the finite element method requires too much calculation time, so it is only applicable for offline 


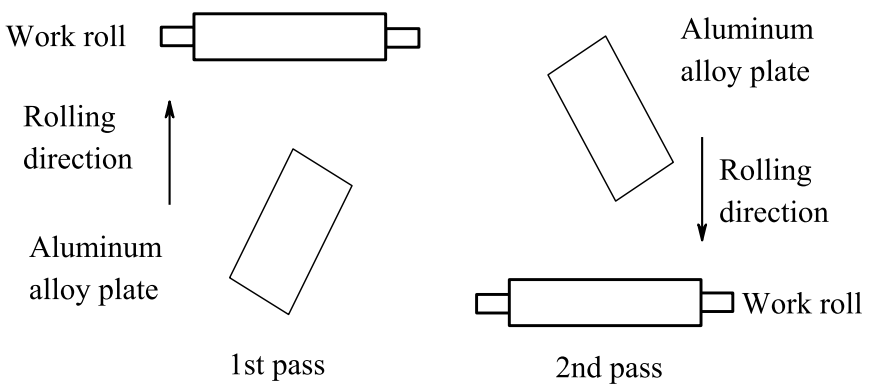

Fig. 1. Schematic diagram of angular rolling process.

calculation. Compared to the finite element method, the influence function method which has high accuracy, requires a shorter calculation time and can be applied in the actual production process. In the calculation process of the influence function method, rolls are considered as simply supported beams and divided into several elements along the axial direction. Elastic deformation of each element is calculated when one element is loaded. In addition, roll flattening caused by the rolling force and contact between the work roll and the backup roll should be considered. Then the deformation of the roll gap can be obtained by superposing the deformation of all elements.

Shohet et al [13] proposed the influence function method in 1968. Jiang et al. [14,15] used influence function method to analyse the mechanics of roll edge contact in cold rolling of thin strips and ultra-thin strips. Liang et al. [16] and Bai et al. [17] used influence function method to analyse the control capability of the strip shape in a sixhigh mill. Liu et al. [18] used influence function method to model the cold rolling and temper rolling processes for thin strips. Zhou et al. [19] calculated the rolling force for cold rolling based on influence function method. He et al. [20] improved the division method in influence function method to obtain an advanced structure of influence function method. Qin et al. [21] and Zhang et al. [22] improved influence function method in a 20-high mill and analysed the shape control capability of the 20-high mill. Chen et al. [23] established models of roll elastic deformation and roll flattening deformation considering work roll contact. Liu et al. [24] established a model for analysing the deformation of an upper roll system and strip in order to analyse the influence of technical parameters on the work roll axial force of a four-high continuous variable crown mill. Chen et al. [25] established a new online elastic deformation model for a four-high cold mill to improve the accuracy of calculation of the mill spring. Chai et al. [26] established an asymmetric deflection model to analyse the influence of deviation on the asymmetric profile of a rolled piece. Ren et al. [27] established a three-dimensional nonlinear simulation model of a six-roll UCM mill to analyse the coupling characteristics of the elastic-plastic deformation of the strip and elastic deformation of the roll.

In previous studies, the influence function method was mostly applied to calculate one section during both hot and cold rolling. However, in the angular rolling process, the volume and location of metal in the deformation zone change with increasing rolling time, so the rolling force and shape of the roll gap also change with rolling time. Thus a

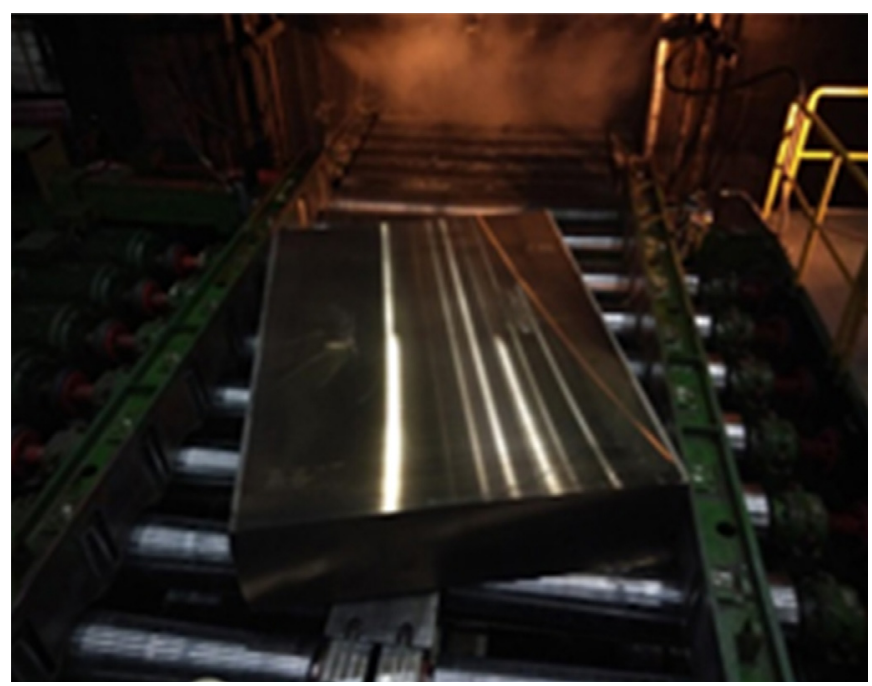

Fig. 2. Aluminium alloy plate used for angular rolling.

continuous calculating model is needed to obtain the whole rolling force and thickness data. Results of rolling force can be applied for setting and supervising rolling parameters, then results of thickness data can be applied for predicting the shape of strips and setting shape control strategies.

In this study, a model for the prediction of rolling force and thickness distribution with influence function method with high accuracy is developed and applied in a continuous rolling process. The continuous rolling process is achieved by calculating the motion of the plate. To obtain the data of the unit rolling force and to validate the accuracy of the mathematical model, an angular rolling experiment is adopted.

\section{Materials and methods}

\subsection{Experiment}

To obtain unit width rolling force data used in the influence function method, experiment was carried on a certain hot rolling line of aluminium alloy plate, as shown in Figure 2. The aluminium alloy plate can be lifted and rotated by crane before being placed on the conveyor roller table. Then the angle between the rolling centre line and the length direction of the aluminium alloy plate is controlled by adjusting the pushing mechanisms located at two sides of the plate, as shown in Figure 2.

The sizes of rolls and plates are listed in Table 1 . The selected grade of aluminium alloy plate is 7075 , which is used widely as sheet in the aerospace industry. The plate is heated to $500^{\circ} \mathrm{C}$ before rolling and is rolled with the rolling speed set to $0.9 \mathrm{~m} / \mathrm{s}$. The reduction in each pass is set as $12 \mathrm{~mm}$ and the angle is set as $10^{\circ}$. The data on the rolling force can be obtained by feedback from hydraulic cylinders for the reduction system.

\subsection{Mathematic model based on influence function method}

In the calculation of the thickness distribution, the programme includes four basic parts: the plate division 
Table 1. Parameters of rolls.

\begin{tabular}{lc}
\hline \multicolumn{1}{c}{ Parameters } & Value $/ \mathrm{mm}$ \\
\hline Backup roll length & 3300 \\
Backup roll diameter & 1400 \\
Work roll length & 3300 \\
Work roll diameter & 700 \\
Length of plate & 2000 \\
Width of plate & 1400 \\
Thickness of plate & 500 \\
\hline
\end{tabular}

model, location updating model, the rolling force calculation model, and the roll deformation calculation model. Except for the formulas with special mark, formulas in this paper are all original. A flow chart of the whole programme is shown in Figure 3.

In the plate division model, the plate is divided into 400 pieces in the rolling direction, numbered 1-400, as shown in Figure 4. The central location of the piece is labelled because it can be used for calculating the location of the rolling force.

The thickness of each piece is the same as the thickness of the plate used in the experiment. The length of each piece is calculated as follows:

$$
l_{\text {piece }}=\frac{\sqrt{l^{2}+b^{2}}}{400} \cdot \cos \left(\arccos \left(\frac{l}{\sqrt{l^{2}+b^{2}}}\right)-\alpha_{\text {angle }}\right),
$$

where $l_{\text {piece }}$ is the length of each piece, $l$ and $b$ are the length and width of the plate, and $\alpha_{\text {angle }}$ is the rotation angle of the plate.

Then the locations of pieces can be obtained by adding up the lengths of the pieces as follows:

$$
L_{\text {piece }, i}=i \cdot l_{\text {piece }}
$$

where $L_{\text {piece, } i}$ is the location of the piece numbered $i$, and $i$ is the number of the piece.

The width of each piece can be calculated as follows:

\section{See equation 3 page below}

where $b_{\text {piece, } i}$ is the width of the piece numbered $i$.

When the division of the plate is completed, the angular rolling process can proceed. The time interval at which the locations of pieces are updated is set as $0.01 \mathrm{~s}$.

In the rolling force calculation model, the length of the deformation zone is a key parameter because it can be used for counting the numbers of pieces located in the

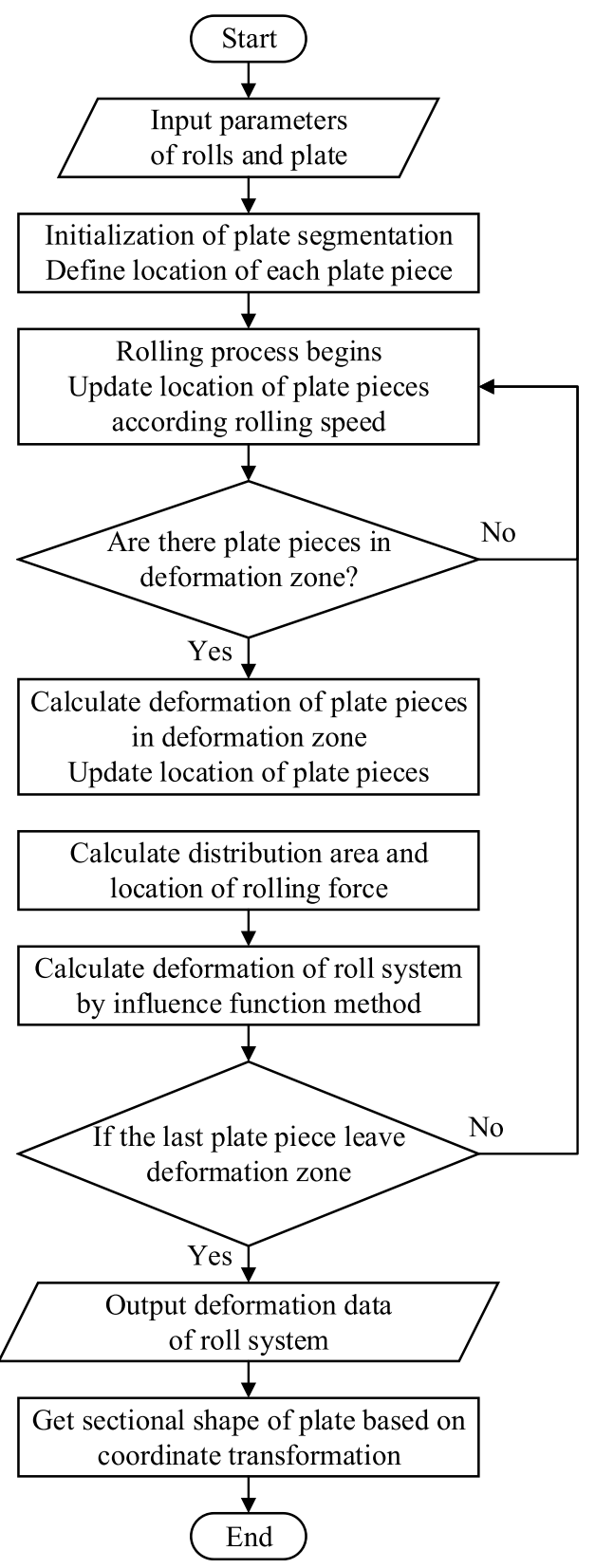

Fig. 3. Calculation flow of prediction model.

deformation zone, and then the width of these pieces can be used for calculating the rolling force. The length of the deformation zone can be obtained as follows:

$$
L_{d}=\sqrt{R^{2}-(R-\Delta H)^{2}}
$$

$$
b_{\text {piece }, i}=\left\{\begin{array}{lr}
\frac{2 L_{\text {piece }, i}}{\sin 2 \alpha_{\text {angle }}} & 0 \leq L_{\text {piece }, i} \leq b \sin \alpha_{\text {angle }} \\
\frac{b}{\cos \alpha_{\text {angle }}} & b \sin \alpha_{\text {angle }} \leq L_{\text {piece }, i} \leq b \cos \alpha_{\text {angle }} \\
\frac{b}{\cos \alpha_{\text {angle }}} \frac{2\left(L_{\text {piece }, i} l \cos \alpha_{\text {angle }}\right)}{\sin 2 \alpha_{\text {angle }}} & L_{\text {piece }, i} \geq b \cos \alpha_{\text {angle }}
\end{array}\right.
$$




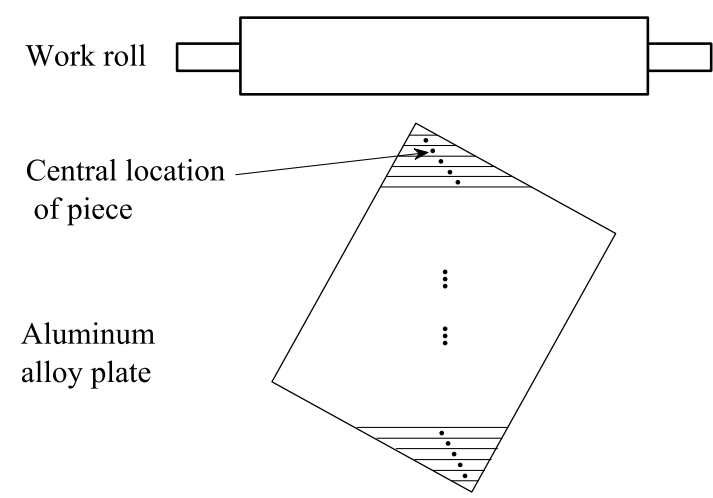

Fig. 4. Schematic diagram of plate segmentation.

where $L_{d}$ is the length of the deformation zone, $R$ is the radius of the work roll, and $\Delta H$ is the reduction.

When the rolling time increases, the locations of the pieces are updated as follows,

$$
L o c_{i}^{\prime}=L o c_{i}+v j \Delta t,
$$

where $L o c^{\prime}{ }_{i}$ is the updated location of the pieces, $L o c_{i}$ is primary location of the pieces, $v$ is velocity of plate, $j$ is numbers of time interval and $\Delta t$ is time interval

According to the geometry of deformation zone and the distance between each piece and the entrance of the deformation zone, the reduction of each piece can be obtained as follows,

$$
\Delta h=\left(L o c_{i}^{\prime}-L o c_{\text {entry }}\right) \frac{H-h}{L_{d}},
$$

where $\Delta h$ is change of thickness of pieces at certain rolling time, $L o c_{\text {entry }}$ is the entry location of deformation zone, $H$ and $h$ are the thickness of plate before and after rolling respectively

Then the sizes of pieces can be calculated according to the law of constant volume. Based on the new sizes of pieces, the area of metal in the deformation zone can be obtained. Then the value and acting area of the rolling force can be calculated according to the rolling force distribution along the contacting arc. The Karman equation is usually used for calculating the rolling force but it suits cold rolling better. Li et al. [28] improved the Karman equation for the hot rolling process. By adopting the improved Karman equation, the rolling force used for roll system deformation can be calculated.

When sizes of pieces change, locations of pieces must be updated again because increasing of length of pieces can lead to motion of pieces towards exit of deformation zone.

Finally, the roll system deformation can be calculated by the influence function method. Considering the asymmetry of the angular rolling process, the roll system model must adopt the sizes of full rolls. The sizes of rolls are

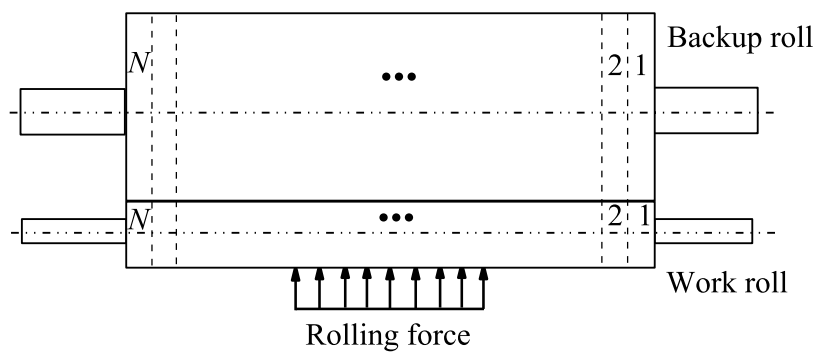

Fig. 5. Schematic diagram of roll system segmentation.

the same as those used in experiment. A diagram of the element division is shown in Figure 5. The number of elements in the axial direction of rolls is set as 400 .

The deformation of the roll system includes the bending of the backup roll and work roll, flattening between the backup roll and work roll, and flattening of the work roll caused by the rolling force.

If $g(i, j)$ is the vertical displacement of a beam at position $i$ caused by the unit load applied to the beam at position $j$, the displacement of the beam at position $i$ caused by the load distribution handled as a number of concentrated loads at the middle of each element can be calculated by the following equation [24]:

$$
y(i)=\sum_{j}^{N} g(i, j) p_{j},
$$

where $g(i, j)$ is defined as the influence function or influence coefficient, $p_{j}$ is the concentrated load at the middle of element $j, N$ is the number of discrete units. The vertical displacement $y(i)$ represents not only the roll deflection, but also the flattening of contact zone.

According to relative theory of mechanics, influence functions of work roll and backup roll deformation can be obtained by roll parameters and the formula as follows,

\section{See equation 8 page below}

where $l$ is length of roll, $E$ is elastic modulus, $I$ is bending modulus, $v$ is Poisson ratio and $D$ is diameter of roll. Calculation of roll flattening is based on research of Chen et al. [23].

The calculation flow chart is shown in Figure 6. When the piece with the highest number exits the deformation zone, the whole programme ends.

\section{Results and discussion}

\subsection{Rolling force}

As shown in Figure 7, rolling force data obtained from the model and experiment are presented. It can be observed that the total rolling force increases rapidly when the

$$
g(i, j)=\left\{\begin{array}{ll}
\frac{x_{i}\left(l x_{j}\right)}{6 E I l}\left[l^{2} x_{i}^{2}\left(l x_{j}^{2}\right)+(1+\nu) D^{2} x_{j}\right] & 0 \leq x_{i}<x_{j} \\
\frac{\left(l x_{j}\right)}{6 E I l}\left[\frac{l\left(x_{i} x_{j}\right)^{3}}{\left(l x_{j}\right)}+\left(l^{2}\left(l x_{j}\right)^{2}\right) x_{i} x_{i}^{3}+(1+\nu) D^{2} x_{j}\right] & x_{j} \leq x_{i}<l
\end{array},\right.
$$




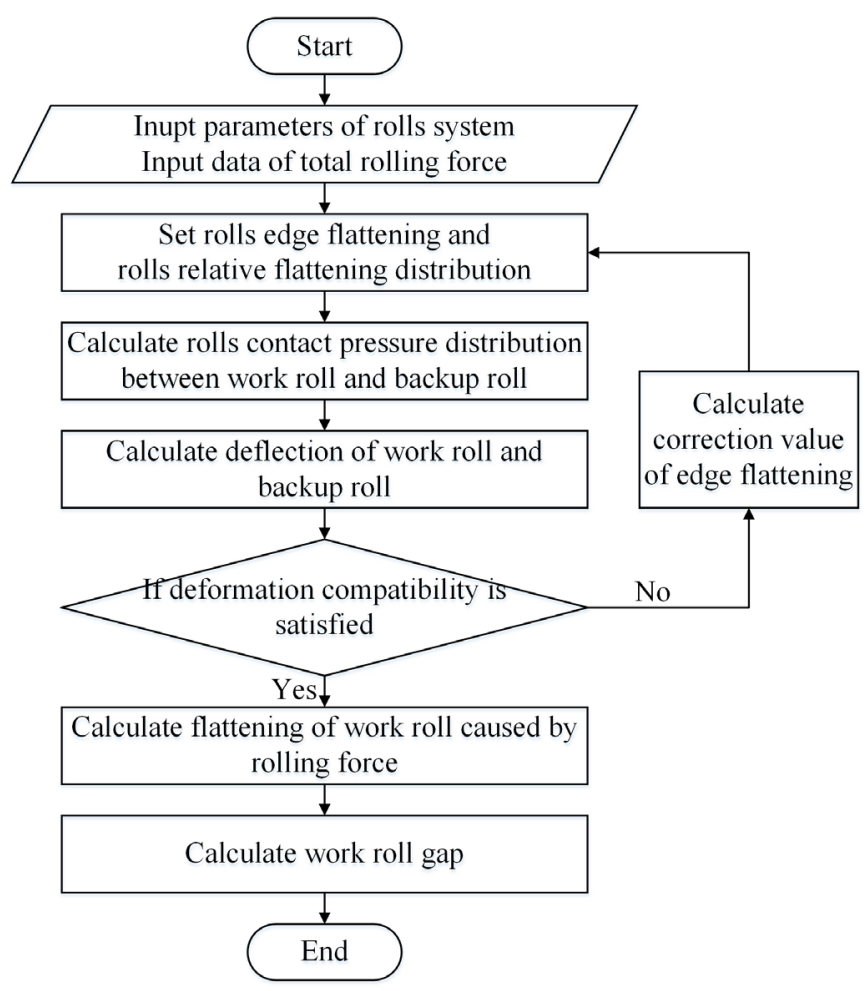

Fig. 6. Calculation flow chart of the influence function method.

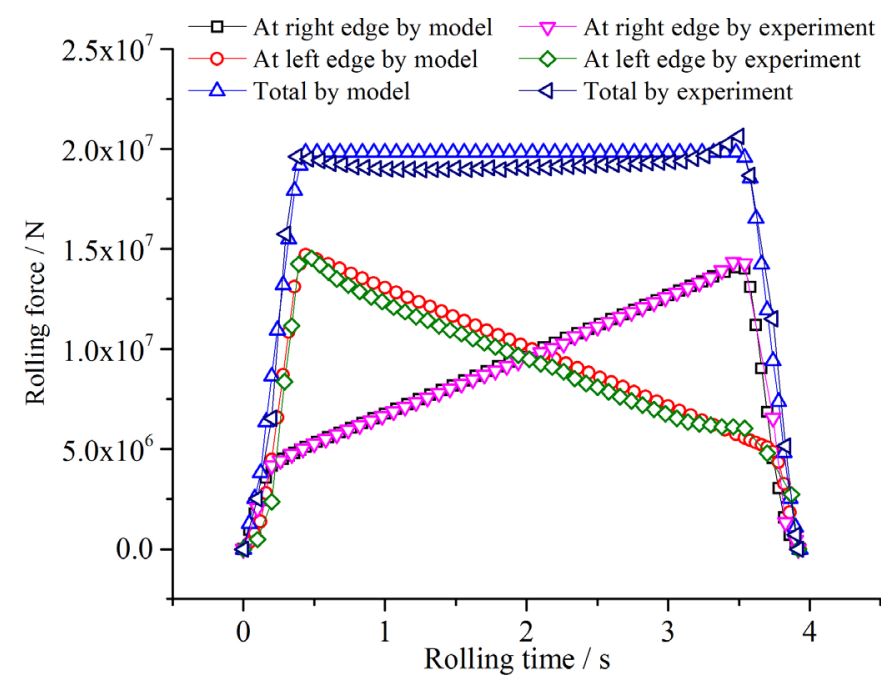

Fig. 7. Rolling force obtained by prediction model and experiment.

rolling process begins, then stays constant, and finally decreases rapidly due to the change of the metal volume in the deformation zone with increasing rolling time. As shown in Figure 4, the location of metal in the deformation zone varies at different rolling times so the rolling forces on each side of the mill are different. It can be observed that at the beginning and end of the angular rolling process, the rolling forces on the two sides have similar changing trends because the metal in the deformation zone is located on both sides of the rolling centre line.

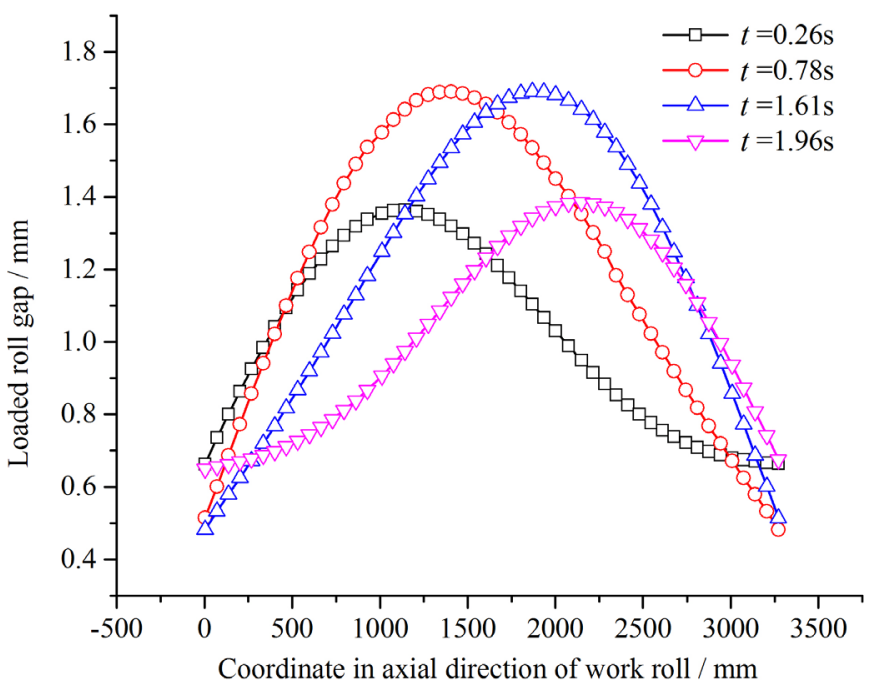

Fig. 8. Roll gap shape at different rolling times.

It is notable that in the angular rolling process, the total rolling force in the experiment decreases gradually after reaching a peak value and then increases gradually to a new peak. The maximal difference between the actual and calculated total rolling forces is $4.5 \%$ of the actual total rolling force and it will not affect the rolling process noticeably. During the rolling time in which the total rolling force is between those two peaks, the volume of metal in deformation remains constant so that angular rolling does not cause a change of the total rolling force. According to rolling theory, the rolling force can be affected by the deformation resistance of the plate, reduction, entry thickness, and so on. Among all the factors, there is one that is not considered in the mathematical model: the fact that the temperature field in the plate that affects the rolling force remarkably. A large number of scholars have researched the temperature field [29-32] in the plate in the rolling process and the results show that the temperature is lower at the edges of the plate than inside the plate. This is because heat transfer occurs between the surfaces of the plate and the environment. So at the head and tail ends, a lower temperature leads to a greater rolling force. In the mathematical model, the temperature is not considered, so the decrease of the rolling force cannot be predicted.

Except for the influence of temperature, the accuracy of the mathematical model for calculating the rolling force is high enough for revealing the changing law of rolling force with rolling time and providing the load conditions used in the roll deformation calculation model.

The rolling force in the second rolling pass is nearly the same as that in the first rolling pass; besides that, the changing trends of the rolling force at the two sides is opposite.

\subsection{Roll gap shape}

With increasing rolling time, the volume and location of metal in the deformation zone change. That leads to a change of the rolling force loaded on the roll system. Then the roll gap shape differs at each rolling time, as shown in Figure 8 . 

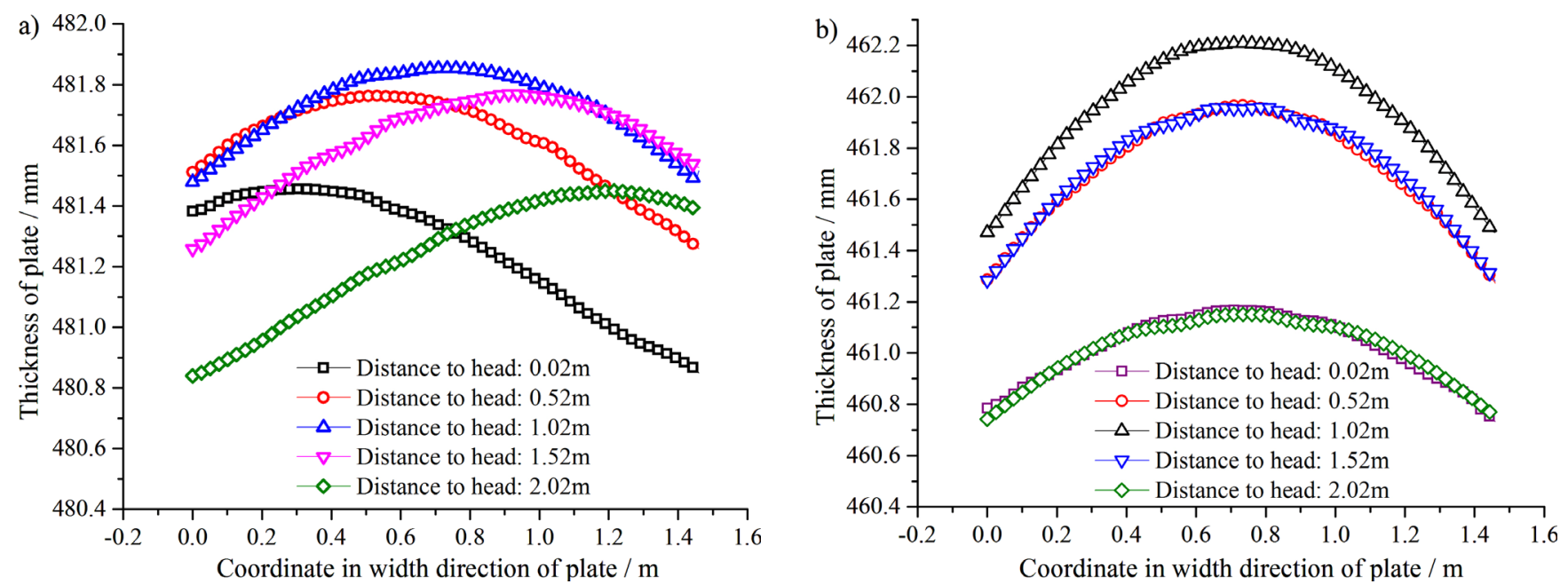

Fig. 9. Thickness distribution in cross sections at different distances from the centre of the plate: (a) after the first pass, (b) after the second pass.

It can be observed that when the rolling times differ, the roll gap shapes are different. When the rolling time is $0.26 \mathrm{~s}$, the volume of metal in the deformation zone is less than that at $0.78 \mathrm{~s}$ and $1.61 \mathrm{~s}$, so the roll system has less elastic deformation and the roll gap shape is comparatively gentle. When the rolling times are at $0.78 \mathrm{~s}$ and $1.61 \mathrm{~s}$, the volume of metal in the deformation zone is almost equal but the locations of metal in the deformation zone are different so the locations of maximal deformations are different. When the rolling time is at $1.96 \mathrm{~s}$, the angular rolling process is about to complete, so there is less metal in the deformation zone and compared to the beginning of the rolling process, the location of the metal is at the right side of the rolling centre line. Then elastic deformation of the roll system is small and maximal deformation appears at the right side of the rolling centre line.

With rolling time increasing, maximal deformation of the roll system changes and the roll gap shape is asymmetrical for most of the rolling time, which leads to an asymmetrical thickness distribution of the plate.

\subsection{Thickness distribution after angular rolling}

In order to obtain the thickness distribution of the plate from the roll gap data, useless data should be eliminated. Then the rest of data need to be rotated by the same angle that through which the plate rotates before angular rolling. Figure 9 shows the thickness distribution in different cross sections after each pass of angular rolling.

It can be observed that the thickness distribution is not symmetric after the first rolling pass. The maximal thickness appears in the middle of the plate. At head and tail ends, the thickness is smaller and the asymmetry is more serious than in the middle of the plate. This distribution can lead to a large wedge, which is defined as a difference in thickness between the two sides of the plate and describes the inhomogeneity of the thickness. According to the thickness data, the maximum of wedge at the head end is $0.471 \times 10^{-3} \mathrm{~m}$ and the minimum of the wedge at the tail end is $-0.526 \times 10^{-3} \mathrm{~m}$. So a second pass of angular rolling with the plate rotating towards the opposite direction is needed to reduce the wedge.

After the second pass of angular rolling, it can be observed that the thickness distributions in the five crosssections are almost symmetrical. The maximum of the wedge is $0.011 \times 10^{-3} \mathrm{~m}$ and is found near the tail end while the minimum is $-0.01 \times 10^{-3} \mathrm{~m}$ and is found near the head end. Considering that the thickness of the plate after angular rolling is about $0.476 \times 10^{-3} \mathrm{~m}$, such wedges can hardly influence the camber that characterizes the bending condition of the plate in the horizontal plane and the lateral motion that characterizes the deviation between the central line of the mill and plate.

According to the results of the mathematical model, the crown distribution can also be obtained. The crown is of great significance and is defined to describe the difference in thickness between the centre and edge of the plate. It can be observed that the crown firstly increases and then decreases from the head end to the tail end of the plate. The range of the crown along the full length is from $0.328 \times 10^{-3}$ to $0.857 \times 10^{-3} \mathrm{~m}$ and is acceptable in the rolling process.

As an asymmetrical rolling process, angular rolling has not been deeply researched. Through the model established in this study, rolling force and distribution of thickness can be obtained for setting rolling process parameters, predicting shape and making shape control strategies. Then more flexible rolling schedules can be obtained for meeting the demand of customized production.

\section{Conclusion}

In this study, a mathematical model based on the influence function method is developed to predict the rolling force and thickness distribution in the full length range. Due to the difficulty of measuring the thickness, only the rolling force data are validated by experiment. The conclusions are as follows: 
- in the angular rolling process, the total rolling force remains almost constant during most of the rolling time. In the middle of the rolling process, the maximal difference between the actual and calculated total rolling forces is $4.5 \%$ of the actual total rolling force. The rolling forces on the right and left sides differ because the volume and location of metal in the deformation zone change with increasing rolling time. In addition, the difference between rolling forces on the right and left leads to a serious asymmetrical roll gap shape;

- after the first pass of angular rolling, the thickness deformation becomes asymmetric and a severe wedge appears at the head and tail ends of the plate. The maximum of the wedge at the head end is $0.471 \times 10^{-3} \mathrm{~m}$ and the minimum of the wedge at the tail end is $-0.526 \times 10^{-3} \mathrm{~m}$. Closer to the middle of plate, the wedge becomes smaller;

- when the angular rolling process finishes, the thickness distribution becomes almost symmetric again. The maximum of the wedge at the tail end is $0.011 \times 10^{-3} \mathrm{~m}$ and the minimum of the wedge at the head end is $-0.01 \times 10^{-3} \mathrm{~m}$. In addition, the range of the crown along the full length is from $0.328 \times 10^{-3}$ to $0.857 \times 10^{-3} \mathrm{~m}$. Then, this model can be applied to develop effective shape-control strategies and more flexible rolling schedules.

Acknowledgments. The authors would like to thank the National Natural Science Foundation of China (No.51674028 and No.51404021) for the support to this research.

\section{References}

1 P.J. Hao, A.R. He, W.Q. Sun, Formation mechanism and control methods of inhomogeneous deformation during hot rough rolling of aluminum alloy plate, Arch. Civ. Mech. Eng. 18 (2018) 245-255. DOI:10.1016/j.acme.2017.07.004

2 J.W. Wu, H.F. Liu, Simulated calculation of rolls' deformation during aluminum strip cold rolling, J. Plast Eng. 24 (2017) 63-68. DOI:10.3969/j.issn.1007-2012.2017.01.010

3 C.G. Sun, H.D. Park, S.M. Hwang, Prediction of three dimensional strip temperatures through the entire finishing mill in hot strip rolling by finite element method, Iron Steel Inst. Jpn 43 (2002) 629-635. DOI:10.2355/isijinterna tional.42.629

4 H.L. Ding, N. Kanamori, T. Honma, S. Kamado, Y. Kojima, FEM analysis for hot rolling process of AM60 alloy, Trans. Nonferrous Met. Soc. China 18 (2008) 242-246. DOI:10.1016/S1003-6326(10)60210-5

5 J. Peng, Y.J. Wang, L.P. Zhong, Y. Sun, L.F. Peng, Three dimensional thermal mechanical coupled simulation of plastic deformation and stress distribution during hot rolling of 5052 aluminum sheet, Trans. Mater. Heat Treat. 36 (2015) 209-213. DOI:10.13289/j.issn.1009-6264.2015. 03.038

6 Y. Song, L.Z. Chen, H. Liu, Simulation of the head and tail defect forming of 3003 aluminum alloy hot rolling and process optimization, J. Plast. Eng. 23 (2016) 76-81. DOI:10.3969/j.issn.1007-2012.2016.04.012
7 Q.D. Zhang, X.F. Zhang, J. Wen, Theory and technology of transverse thickness deviation control for DI tinplate during tandem cold rolling, J. Mech. Eng. 49 (2013) 30-38. DOI:10.3901/JME.2013.24.030

8 Q.D. Zhang, X.M. Sun, J. Bai, Analysis of rolls' elastic deformation on CVC 6-h mill by FEM, J. Mech. Eng. 18 (2007) 789-792. DOI:10.3321/j.issn:1004-132X.2007.07.009

9 X.T. Li, Z.H. Wu, F.S. Du, J.N. Sun, FEA on rolls' deformation in rolling process of 4-roll skin miller, J. Plast. Eng. 15 (2008) 126-130

10 Q. Lu, A.R. He, J. Shao, Q. Yang, Modelling the edge contact of work rolls in hot rolling of ultra-thin strip, J. Plast. Eng. 17 (2010) 95-99. DOI:10.3969/j.issn.1007-2012.2010.02.018

11 J.W. Wu, H.F. Liu, Simulated calculation of rolls' deformation during aluminum strip cold rolling, J. Plast. Eng. 24 (2017) 63-68. DOI:10.3969/j.issn.1007-2012.2017.01.010

12 W.Q. Sun, B. Li, J. Shao, A.R. He, Research on crown and flatness allocation strategy of hot rolling mills, Int. J. Simul. Model. 15 (2016) 327-340. DOI:10.2507/IJSIMM15(2)CO6

13 K.N. Shohet, N.A. Townsend, Roll bending methods of crown control in four-high plate mills, J. Iron Steel Inst. 206 (1968) 1088

14 Z.Y. Jiang, D. Wei, A.K. Tieu, Analysis of cold rolling of ultra-thin strip, J. Mater. Process. Technol. 209 (2009) 45844589. DOI:10.1016/j.jmatprotec.2008.10.035

15 Z.Y. Jiang, H.T. Zhu, A.K. Tieu, Mechanics of roll edge contact in cold rolling of thin strip, Int. J. Mech. Sci. 48 (2006) 697-706. DOI:10.1016/j.ijmecsci.2006.01.017

16 X.G. Liang, Preset model of bending force for six-high tandem cold rolling mill, Iron Steel 49 (2014) 40-43. DOI:10.13228/j.boyuan.issn0449-749X.20140218

17 J.L. Bai, J.S. Wang, G.D. Wang, X.H. Liu, Analysis of roll force distribution between rolls on a six-high mill, J. Northeast. Univ. (Nat. Sci.) $26 \quad$ (2005) 133-136. DOI:10.3321/j.issn:1005-3026.2005.02.009

18 Y.l. Liu, W.H. Lee, Mathematical model for the thin strip cold rolling and temper rolling process with the influence function method, Iron Steel Inst. Jpn. 45 (2005) 1173-1178. DOI:10.2355/isijinternational.45.1173

19 H. Zhou, J. L. Bai, Rolling force calculation for strip cold rolling based on influence function method, Appl. Mech. Mater. 633-634 (2014) 791-794. DOI:10.4028/www.scientif ic.net/AMM.633-634.791

20 C.Y. He, Z.J. Jiao, X.J. Wang, Study on advanced structure with application of improved influence function method in solving roll system deformation based on material properties, Adv. Mater. Res. 700 (2013) 98-102. DOI:10.4028/www. scientific.net/AMR.700.98

21 J. Qin, Q. Miao, The matrix iteration method for elastic deformation of multi-roll mill based on influence function method, Eng. Mech. 30 (2013) 271-276. DOI:10.6052/j. issn.1000-4750.2012.01.0038

22 Q.D. Zhang, C. Dai, J. Wen, X.F. Zhang, J. Qin, Simulation and analysis on shape control behavior of 20-h Sendzimir mill, Steel Roll. 30 (2013) 1-6. DOI:10.13228/j.boyuan. issn1003-9996.2013.03.002

23 J.S. Chen, J. Wang, W.Q. Liu, Study on models of work roll contact for tandem cold rolling process, Steel Roll. 33 (2016) 27-33. DOI:10.13228/j.boyuan.issn.1003-9996.20150171

24 G.M. Liu, Y.G. Li, Q.X. Huang, X. Yang, Axial force analysis and roll contour configuration of four-high CVC mill, Math. Probl. Eng. (2018). DOI:10.1155/2018/7527402 
25 S.Z. Chen, L.G. Peng, L. Wang, D.H. ZAHANG, Online model research for elastic deformation of 4-high cold mill, J. Cent. South Univ. (Sci. Technol.) 6 (2017) 1432-1439. DOI:10.11817/j.issn.1672-7207.2017.06.004

26 X.J. Chai, H.B. Li, J. Zhang, Y.Z. Zhou, W.D. Hu, P.W. Zhang, Influence of the deviation of rolled piece on its asymmetric degree of profile in hot rolling, in: 6th International Conference on Manufacturing Science and Engineering, 2015, pp. 1063-1066. DOI:10.2991/icmse15.2015.193

27 X.Y. Ren, Y.K. Zheng, H. Zhou, H.M. Gao, X.L. Luo, H.G. Huang, Analysis and application of strip shape control performance of 1420 six-high UCM cold tandem mill, Heavy Mach. 5 (2016) 10-16. DOI:10.13551/j.cnki.zxjxqk.2016. 05.003

28 W.G. Li, L.Y. Lu, C. Liu, X.H. Liu, Roll force model in consideration of slipping and sticking friction during strip rolling process, J. Cent. South Univ. (Sci. Technol.) 47
(2016) 4021-4027. DOI:10.11817/j.issn.1672-7207.2016. 12.009

29 J. Liu, D.H. Mao, L.H. Zhan, Numerical simulation of temperature field in hot rolling process of extra-thick plate of 2124 aluminum alloy, Mater. Mech. Eng. 33 (2009) 86-89

30 M. Bagheripoor, H. Bisadi, Effects of rolling parameters on temperature distribution in the hot rolling of aluminum strips, Appl. Therm. Eng. 31 (2011) 1556-1565. DOI:10.1016/j.applthermaleng.2011.01.005

31 T. Zhang, Y.X. Wu, H. Gong, W.Z. Shi, F.M. Jiang, S.S. Jiang, Analysis of temperature asymmetry of aluminum alloy thick plate during snake hot rolling, Int. J. Adv. Manuf. Technol. 87 (2016) 941-948. DOI:10.1007/s00170016-8536-1

32 J.X. Niu, J. Li, J.L. Sun, F.Q. Zhen, Coupled thermosmechanical analysis for hot continuous rolling of 3104 aluminum strip, J. North Univ. China (Nat. Sci. Edition) 37 (2016) 193-197. DOI:10.3969/j.issn.1673-3193.2016.02.018

Cite this article as: P. Hao, A. He, W. Sun, Predicting model of thickness distribution and rolling force in angular rolling process based on influence function method, Mechanics \& Industry 19, 302 (2018) 